\title{
VARIAÇÃO RADIAL DA DENSIDADE BÁSICA E DIMENSÕES CELULARES DE Croton floribundus
}

\author{
Israel Luiz de Lima ${ }^{1}$, Beatriz Ribeiro Zanon ${ }^{2}$, Eduardo Luiz Longui ${ }^{3}$, Sandra Monteiro Borges Florsheim ${ }^{4}$ \\ ${ }^{1}$ Eng. Florestal, Dr., Instituto Florestal de São Paulo, São Paulo, SP, Brasil - israelluizde.lima@ yahoo.com.br \\ ${ }^{2}$ Acadêmica do curso de Ciências Biológicas, UNINOVE, São Paulo, SP, Brasil - bia_biologi@ yahoo.com.br \\ ${ }^{3}$ Biólogo, Dr., Instituto Florestal de São Paulo, São Paulo, SP, Brasil - elongui @if.sp.gov.br \\ ${ }^{4}$ Bióloga, M.Sc., Instituto Florestal de São Paulo, São Paulo, SP, Brasil - sflorsheim @if.sp.gov.br
}

Recebido para publicação: 19/03/2009 - Aceito para publicação: 11/12/2009

\begin{abstract}
Resumo
Croton floribundus (capixingui) é encontrado nos estados de Minas Gerais, São Paulo e Paraná. Face à necessidade de novos conhecimentos das propriedades desta madeira, em condições de laboratório, objetivou-se estudar a variação radial da densidade básica e as dimensões celulares desta espécie, oriunda de população natural. De cinco árvores, com DAP médio de 20,35 cm, coletou-se um disco de $7 \mathrm{~cm}$ de espessura na região do DAP. Estas árvores estavam localizadas no Parque Estadual da Cantareira, do Instituto Florestal do Estado de São Paulo. De cada disco foram retiradas amostras representando as posições próximo à medula, região intermediária e próximo à casca, para o estudo da variação radial, das seguintes variáveis: densidade básica; comprimento, diâmetro e frequência de vasos; altura, largura e freqüência de raios; comprimento, diâmetro, espessura da parede e lume das fibras. Os resultados indicaram que ocorreu uma tendência de aumento no diâmetro de vasos e uma diminuição na frequência de raios no sentido medula-casca, e para as demais variáveis não ocorreu a mesma tendência.
\end{abstract}

Palavras-chave: Croton floribundus; células da madeira; variação radial.

\section{Abstract}

Radial variation of the basic density and cellular dimensions of Croton floribundus. Croton floribundus (capixingui) is found in the States of Minas Gerais, São Paulo and Paraná. In view of the necessity of new knowledge of the wood properties in laboratory conditions, this work aimed to study the radial variation of the basic density and cellular dimensions of this species. Discs from five trees with average DBH of 20,35 cm, with thickness of $7 \mathrm{~cm}$, were collected at DBH height. The trees came from the Cantareira State Park, property of the Forestry Institute of Sao Paulo State. From each disc, samples were removed, representing the positions pith, intermediate and bark, to study the radial variation of the following variables: basic density; length, diameter, and vessels frequency; length, width, and rays frequency; wall length, diameter, and thickness; and lumen diameter. The results indicated that occurred an increase tendency in the vessels diameter and reduction in the ray frequency from the pith to the bark; the other variables did not show this trend.

Keywords: Croton floribundus; wood cells; pith-bark variation.

\section{INTRODUÇÃO}

O gênero Croton é representado por cerca de 600 espécies naturais das regiões tropicais do mundo, entre as quais se encontra a espécie Croton floribundus Spreng, popularmente chamada de capixingui, capexingui, tapixingui, capoeira-preta, urucurana, sangra-d água, lixeira, sangue-de-dragão, sangue-de-drago, velame e velame-de-cheiro, variando de acordo com a região em que se encontra (CARVALHO, 2003). Essa espécie é pioneira e comum na vegetação secundária da Floresta Estacional Semidecidual, distribuindo-se com frequência em matas ou capoeirões dos estados de Minas Gerais, São Paulo e Paraná (LORENZI, 2002; CARVALHO, 2003).

Segundo Durigan et al. (2002), C. floribundus é uma espécie pioneira, heliófita, de crescimento muito rápido e ciclo de vida curto, muito frequente na floresta estacional semidecidual, ocorrendo eventualmente em cerrados. Na floresta primária, encontram-se poucos indivíduos, de grande porte, no 
estrato superior do dossel. É muito abundante em formações secundárias, cicatrizando clareiras e proliferando em bordas de mata. Trata-se de uma espécie prioritária para reflorestamentos mistos de áreas degradadas, tanto protetivos como comerciais, como sombreadora de espécies em estágios mais avançados de sucessão (DURIGAN et al., 2002). A árvore como planta pioneira tolerante em áreas abertas é útil para plantios mistos em reflorestamentos de áreas degradadas de preservação permanente (LORENZI, 2002). O capixingui apresenta crescimento moderado, com incremento médio anual em volume com casca de até $6,40 \mathrm{~m}^{3}$.ha ${ }^{-1}$.ano (CARVALHO, 2003).

De acordo com Mainieri; Chimelo (1989) e Carvalho (2003), a madeira de C. floribundus apresenta densidade aparente em torno de 0,50 a $0,60 \mathrm{~g} \cdot \mathrm{cm}^{-3}$, em $15 \%$ de umidade. Sua retração volumétrica é considerada média (14\%). O alburno e o cerne não são diferenciados, de coloração begeclara ou bege-rosada, uniforme. Superfície lisa ao tato e pouco lustrosa; textura média; grã direita; cheiro e gosto imperceptíveis. A madeira é indicada para caixotaria leve, artefatos de madeira, tamancos, fabricação de fósforo, chapas de partículas, tábuas, pontaletes e revestimentos internos na construção civil. É adequada para a fabricação de celulose e papel, por ser facilmente desfibrável e por ser moderadamente pesada, de cor clara e resistência mecânica entre baixa e média. Sua madeira não possui valor comercial expressivo. Sua resistência é considerada muito baixa ao ataque de organismos xilófagos, porém demonstra alta permeabilidade às soluções preservantes (MAINIERI; CHIMELO, 1989).

Segundo Cruz et al. (2003), tanto as propriedades físicas quanto as mecânicas apresentam maiores variações na direção da medula para a casca do que da base para o topo das árvores, mostrando a importância do conhecimento das variações radiais nas toras, para o estudo de qualidade da madeira.

A madeira juvenil é formada pelo câmbio nos primeiros anos de crescimento do tronco e situa-se em volta da medula. Esse período de crescimento é chamado de juvenilidade. Nas toras de árvores muito jovens, quase toda a madeira é juvenil, enquanto que nas toras de idade mais avançada essa característica é encontrada apenas em uma porção muito pequena do centro. O período de juvenilidade varia conforme a espécie e pode ser influenciado pelas condições ambientais. A madeira adulta é formada após o período de juvenilidade e, em geral, as células dessa madeira alcançam suas dimensões máximas, que se mantêm mais ou menos constantes, exceto quando são influenciadas drasticamente pelas condições ambientais (JANKOWSKY, 1979; ZOBEL, 1981; HILLIS; BROWN, 1984).

A grande diferença em termos de madeira juvenil em relação à madeira adulta está na magnitude das alterações anatômicas e físicas, que ocorrem no sentido da medula para a casca do tronco. As características anatômicas envolvidas nas mudanças são: comprimento de fibra, ângulo microfibrilar, proporções dos tipos de células, diâmetro celular e espessura da parede celular. Outros fatores, tais como massa específica, resistências e retratilidade modificam-se em consequência da variação de tais características anatômicas (OLIVEIRA; SILVA, 2003).

Segundo Zobel; Buijtenn (1989), aumento na densidade da madeira e comprimento das fibra no sentido da medula para a casca, obtido por meio de crescimento lento, pode resultar em uma madeira de melhor qualidade. Isso pode ser conseguido com a redução da taxa de crescimento inicial pelo controle da densidade populacional inicial e retardando a programação de possíveis desbastes, o que resultaria em uma menor proporção de madeira juvenil em favor de um aumento posterior da densidade. $\mathrm{O}$ crescimento rápido, obtido em idade mais avançada por meio de operações silviculturais, tenderá a reduzir a densidade perto da periferia, como também produzir uma madeira com reduzido gradiente de densidade na direção da medula para casca (HANS et al., 1972).

Este estudo teve como objetivo caracterizar a variação radial da densidade básica e dimensões celulares de C. floribundus em condições naturais.

\section{MATERIAL E MÉTODOS}

As amostras de madeira de C. floribundus foram coletadas no Parque Estadual da Cantareira, São Paulo, SP, nas coordenadas geográficas $23^{\circ} 22^{\prime}$ Lat. S, $46^{\circ} 36^{\prime}$ long. W, a uma altitude média de $850 \mathrm{~m}$.

Devido à ocorrência em floresta natural, não foi possível determinar a idade dos indivíduos, no entanto buscou-se uma padronização realizando a coleta em árvores com cerca de $20 \mathrm{~cm}$ de DAP (diâmetro a altura do peito; $1,30 \mathrm{~cm}$ do solo). As coletas foram realizadas em cinco árvores. De cada uma foi retirado um disco de $7 \mathrm{~cm}$ de espessura no DAP. De cada disco retiraram-se amostras, representativas das posições próximo à medula, intermediária (centro) e próximo à casca (Figura 1). 


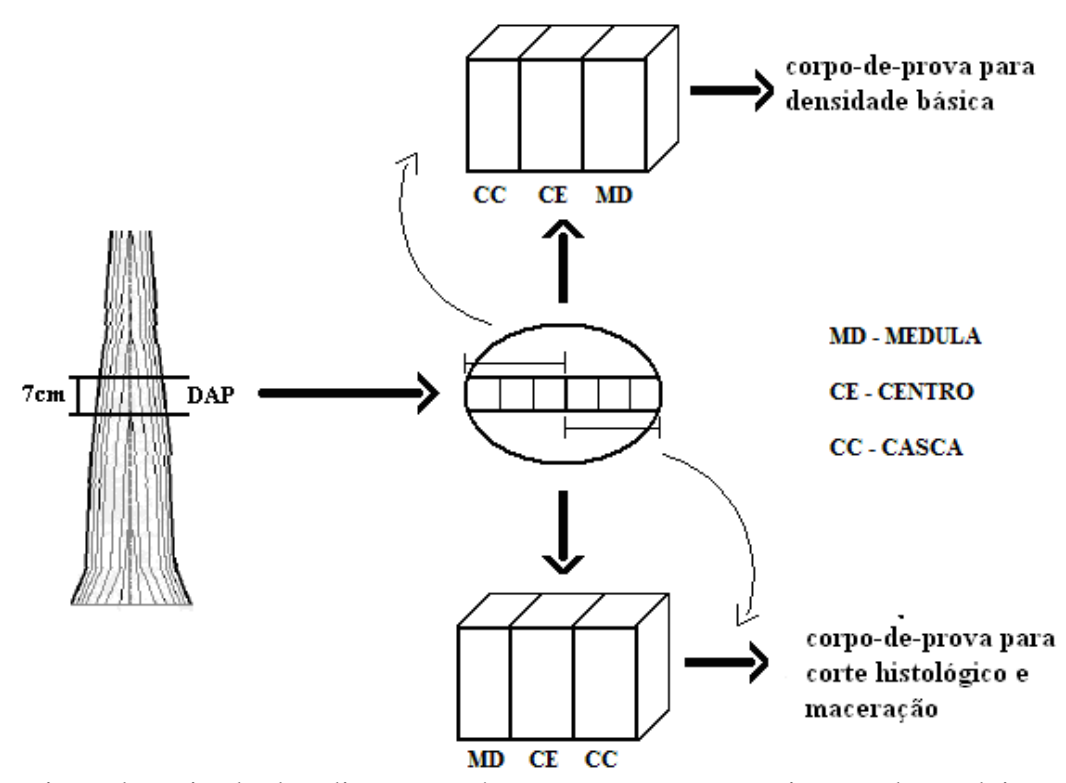

Figura 1. Posição de retirada dos discos nas árvores para a caracterização da madeira. Figure 1. Sampling position of the discs in the trees for wood characterization.

A partir das amostras, foram tirados corpos de prova com dimensões de aproximadamente $2 \times 2$ x $3 \mathrm{~cm}$ de aresta, para o estudo da variação medula-casca das seguintes variáveis: densidade básica (DB), comprimento dos elementos de vaso $(\mathrm{CV})$, diâmetro dos vasos (DV), frequência de vasos (FV), altura dos raios (AR), largura dos raios (LR), frequência dos raios (FR), comprimento das fibras (CF) e espessura da parede das fibras (EP).

Para obtenção de secções histológicas, corpos de prova $\left(2 \mathrm{~cm}^{3}\right)$ foram amolecidos por meio de cozimento em água e glicerina (4:1), até apresentarem condições ideais ao corte. Secções entre 20 e $30 \mu \mathrm{m}$ nos planos transversal e longitudinal tangencial foram obtidas com auxílio de micrótomo de deslize marca Leitz 1208. As secções foram clarificadas com hipoclorito de sódio (60\%), lavadas em água, coradas com safranina e azul de astra a 1\% (9:1) (JOHANSEN, 1940) e montadas em solução de água com glicerina.

O lenho dissociado foi preparado de acordo com o método de Franklin modificado (BERLYN; MIKSCHE, 1976), corado com safranina alcoólica e montado em solução de água com glicerina (1:1).

A terminologia empregada para as análises anatômicas seguiu as recomendações do IAWA Committee (1989). Todas as mensurações foram realizadas em microscópio equipado para captura de imagens e sistema de medições (marca Olympus modelo BX 50, com software de análise de imagens Image - Pro Express versão 4.0). Para todas as características foi adotado $\mathrm{n}=25$.

Para determinação da densidade básica, foi utilizado o método da balança hidrostática, conforme Foelkel et al. (1971). Os corpos de prova foram saturados por um período de aproximadamente dois meses, para se poder obter a massa úmida e imersa de cada corpo de prova. Posteriormente, eles foram secos em estufa até atingirem o peso de massa seca constante a $105 \pm 3{ }^{\circ} \mathrm{C}$.

Foi utilizada a expressão (1):

$$
D B=\frac{\boldsymbol{P}_{s}}{\boldsymbol{P}_{u}-\boldsymbol{P}_{i}}
$$

Em que: DB: densidade básica $\left(\mathrm{g} \cdot \mathrm{cm}^{-3}\right)$

$$
\begin{aligned}
& \mathrm{P}_{\mathrm{s}} \text { : massa seca }(\mathrm{g}) \\
& \mathrm{P}_{\mathrm{u}} \text { : massa saturada }(\mathrm{g}) \\
& \mathrm{P}_{\mathrm{i}} \text { : massa imersa }(\mathrm{g})
\end{aligned}
$$


Todos os resultados foram submetidos ao teste de Hartley, para verificação da homogeneidade das variâncias. Posteriormente, foram examinados pelo teste $\mathrm{F}$ de análise de variância, considerando o delineamento experimental de blocos casualizado. O teste de Tukey, para comparação entre as médias, foi aplicado sempre que o teste $\mathrm{F}$ acusasse diferença entre tratamentos ao nível de $5 \%$ de probabilidade. Os resultados obtidos das variáveis foram analisados estatisticamente com o auxílio do procedimento estatístico PROC GLM (SAS, 1999).

\section{RESULTADOS E DISCUSSÃO}

Nas tabelas 1 e 2, têm-se um resumo da análise de variância para densidade básica e elementos celulares de $C$. floribundus e os seus respectivos valores médios e desvio padrão.

Tabela 1. Resumo da análise de variância para densidade básica e elementos anatômicos de Croton floribundus.

Table 1. Summary of the variance analysis for basic density and cellular dimensions of Croton floribundus.

\begin{tabular}{|c|c|c|c|c|}
\hline Variável & Posição radial & Média & Tukey 5\% & Quadrado médio \\
\hline \multirow{3}{*}{ Densidade básica $\left(\mathrm{g} . \mathrm{cm}^{-3}\right)$} & medula & 0,47 & $\mathrm{a}$ & \multirow{3}{*}{$0,0016^{\mathrm{n} . \mathrm{s}}$} \\
\hline & centro & 0,48 & a & \\
\hline & casca & 0,50 & $\mathrm{a}$ & \\
\hline \multirow{3}{*}{ Comprimento de fibra (mm) } & medula & 1,38 & $\mathrm{a}$ & \multirow{3}{*}{$11447,05^{\text {n.s. }}$} \\
\hline & centro & 1,41 & a & \\
\hline & casca & 1,32 & $\mathrm{a}$ & \\
\hline \multirow{3}{*}{ Espessura de parede da fibra $(\mu \mathrm{m})$} & medula & 4,87 & $\mathrm{a}$ & \multirow{3}{*}{$1,2158^{\mathrm{n} . \mathrm{s}}$} \\
\hline & centro & 5,18 & a & \\
\hline & casca & 5,85 & $\mathrm{a}$ & \\
\hline \multirow{3}{*}{ Comprimento de vaso $(\mu \mathrm{m})$} & medula & 736,59 & $\mathrm{a}$ & \multirow{3}{*}{$1450,50^{\text {n.s. }}$} \\
\hline & centro & 746,53 & $\mathrm{a}$ & \\
\hline & casca & 769,78 & a & \\
\hline \multirow{3}{*}{ Diâmetro de vaso $(\mu \mathrm{m})$} & medula & 102,45 & $\mathrm{~b}$ & \multirow{3}{*}{$1319,21^{* *}$} \\
\hline & centro & 120,93 & $a b$ & \\
\hline & casca & 134,82 & $\mathrm{a}$ & \\
\hline \multirow{3}{*}{ Frequência de vaso $\left(\mathrm{n}^{\mathrm{o}} \cdot \mathrm{mm}^{-2}\right)$} & medula & 13,34 & $\mathrm{a}$ & \multirow{3}{*}{$9,84^{\mathrm{n} . \mathrm{s}}$} \\
\hline & centro & 11,08 & a & \\
\hline & casca & 10,78 & $\mathrm{a}$ & \\
\hline \multirow{3}{*}{ Altura de raio $(\mu \mathrm{m})$} & medula & 517,15 & $\mathrm{a}$ & \multirow{3}{*}{$2466,63^{\text {n.s. }}$} \\
\hline & centro & 474,16 & a & \\
\hline & casca & 505,34 & a & \\
\hline \multirow{3}{*}{ Largura de raio $(\mu \mathrm{m})$} & medula & 28,35 & $\mathrm{a}$ & \multirow{3}{*}{$11,9871^{\mathrm{n} . \mathrm{s}}$} \\
\hline & centro & 28,02 & $\mathrm{a}$ & \\
\hline & casca & 30,85 & $\mathrm{a}$ & \\
\hline \multirow{3}{*}{ Frequência de raio $\left(\mathrm{n}^{\circ} \mathrm{mm}^{-1}\right)$} & medula & 10,52 & $\mathrm{a}$ & \multirow{3}{*}{$20,1108^{* *}$} \\
\hline & centro & 7,65 & $\mathrm{~b}$ & \\
\hline & casca & 6,65 & $\mathrm{~b}$ & \\
\hline
\end{tabular}

${ }^{\text {n.s: }}$ não significativo; ${ }^{* *}$ : significativo ao nível de $1 \%$ de probabilidade. Médias seguidas de letras diferentes em uma mesma coluna diferem entre si (ao nível de $5 \%$ de probabilidade).

A densidade básica não apresentou diferenças significativas ao nível de $5 \%$ de probabilidade em relação à posição radial (Tabela 1). Isso pode ser explicado por uma possível diferença nas idades entre as árvores amostradas de cada local. $\mathrm{O}$ valor médio da densidade básica $\left(0,48 \mathrm{~g} . \mathrm{cm}^{-3}\right)$ está acima do valor encontrado por Gouveia et al. (2007), que foi $0,44 \mathrm{~g} . \mathrm{cm}^{-3}$ (Tabela 1). Mainieri; Chimelo (1989) encontraram 0,60 g.cm $\mathrm{cm}^{-3}$ para a densidade aparente. Tertuliano et al. (2003) encontraram valores de densidade básica variando de 0,63 a $0,68 \mathrm{~g} . \mathrm{cm}^{-3}$ para Croton sonderianus. Os valores de comprimento e espessura das fibras também não apresentaram diferenças significativas entre as posições radiais, ao nível 
de 5\% de probabilidade (Tabela 1). O comprimento médio das fibras foi de 1,36 mm, acima do encontrado por Carvalho (2003), que foi de $0,9 \mathrm{~mm}$ (Tabela 2). Para a espessura da parede da fibra, o valor médio foi de $5,3 \mu \mathrm{m}$, portanto dentro da variação encontrada por Gouveia et al. (2007), que foi de 3 a $7 \mu \mathrm{m}$ (Tabela 2).

Tabela 2. Médias e desvio padrão (DP) da densidade básica e elementos anatômicos de Croton floribundus.

Table 2. Average and standard deviation (DP) of the basic density and cellular dimensions of Croton floribundus.

\begin{tabular}{lcc}
\hline Variável & Média & DP \\
\hline Densidade básica $\left(\mathrm{g} . \mathrm{cm}^{-3}\right)$ & 0,48 & 0,0288 \\
Comprimento de fibra $(\mathrm{mm})$ & 1,36 & 0,0842 \\
Espessura de parede da fibra $(\mu \mathrm{m})$ & 5,30 & 0,9138 \\
Comprimento de elemento de vaso $(\mu \mathrm{m})$ & 750,96 & 88,1253 \\
Diâmetro de vaso $(\mu \mathrm{m})$ & 119,40 & 17,4568 \\
Frequência de vaso $\left(\mathrm{n}^{\mathbf{o}} . \mathrm{mm}^{-2}\right)$ & 11,73 & 1,9905 \\
Altura de raio $(\mu \mathrm{m})$ & 498,88 & 49,0448 \\
Largura de raio $(\mu \mathrm{m})$ & 29,07 & 3,7411 \\
Frequência de raio $\left(\mathrm{n}^{\mathbf{o}} . \mathrm{mm}^{-1}\right)$ & 8,28 & 1,8054 \\
\hline
\end{tabular}

Observou-se que a densidade básica e a espessura da parede da fibra apresentaram uma tendência de aumento no sentido da medula para a casca. Porém não foram detectadas diferenças estatisticamente significativas (Tabela 1). Essa mesma tendência foi observada por Butterfield et al. (1993). Para o comprimento das fibras, não ocorreu nenhuma tendência de aumento ou diminuição no sentido medula-casca. Tomazello Filho (1983) verificou um aumento, no sentido medula-casca, do comprimento e espessura da parede da fibra para algumas espécies do gênero Eucalyptus. Esse comportamento se verifica na maioria das espécies de reflorestamento em estudos semelhante a este. Bosman et al. (1994) observaram aumento na densidade no sentido da casca associado a um aumento na espessura da parede das fibras.

Para os elementos de vaso, pode-se observar que o comprimento e frequência de vasos não diferiram significativamente na variação radial (Tabela 1). Porém para o diâmetro de vasos ocorreu diferença significativa. Ainda que não comprovado estatisticamente, o comprimento dos elementos de vaso apresentou tendência de aumento no sentido radial, enquanto que a frequência apresentou uma tendência inversa, mesmo padrão observado por Arachuku (1987) (Tabela 1). Para o diâmetro de vasos, ocorreu aumento no sentido medula-casca, sendo que a posição medula diferiu significativamente da posição casca (Tabela 1 e Figura 2 A, C e E). Pollito (2004) encontrou valores de 581,19 $\mu \mathrm{m}, 55,32 \mu \mathrm{m}$ e 16 a $21 / \mathrm{mm}^{2}$, respectivamente, para comprimento, diâmetro e frequência de vasos de C. floribundus, material coletado no estado do Acre, sendo que o comprimento e o diâmetro são menores e a frequência é maior do que o obtido no presente estudo. Isso também pode ser explicado por uma possível diferença entre as idades das árvores coletadas nos diferentes locais. Resultados semelhantes aos encontrados para C. floribundus foram descritos por Denne; Hale (1999). Os autores verificaram variação da densidade no sentido radial em Nothofagus nervosa, associada a um aumento na parede das fibras e no diâmetro dos vasos.

Para as variáveis altura e largura dos raios não se observou diferenças entre as posições radiais, enquanto para a frequência ocorreu diferença significativa (Tabela 1). Os resultados encontrados, no sentido radial, estão de acordo com Urbinati et al. (2003). A altura e a largura dos raios não apresentaram uma tendência definida (Tabela 1). Porém para a frequência houve uma redução no sentido medula-casca (Tabela 1 e Figura 2 B, D e F). Os autores verificaram, para Terminalia ivorensis, que a redução na frequência de raios próximos ao câmbio pode ser consequência da redução do número de células iniciais radiais, com aumento do número de células iniciais fusiformes e, consequentemente, aumento na proporção de fibras nessa região.

Em geral, densidades mais altas foram relacionadas com a baixa frequência de vasos (BASSON, 1987; RAO et al., 1997; GREEN et al., 1999), maiores proporções, comprimento e espessura de parede das fibras (BASSON, 1987; DOWNES et al., 1997) e raios de menores dimensões e em menor frequência (FUJIWARA et al., 1991). O aumento na densidade em C. floribundus da medula para a casca pode ser explicado, em parte, pela redução na frequência dos raios. De acordo com Wiemann; Williamson (1988), 
espécies pioneiras como $C$. floribundus tendem a apresentar aumento na densidade da medula para a casca, uma vez que, ao colonizar um ambiente, crescem rapidamente no início do desenvolvimento, o que ocasiona um tronco mais frágil e com menor densidade.
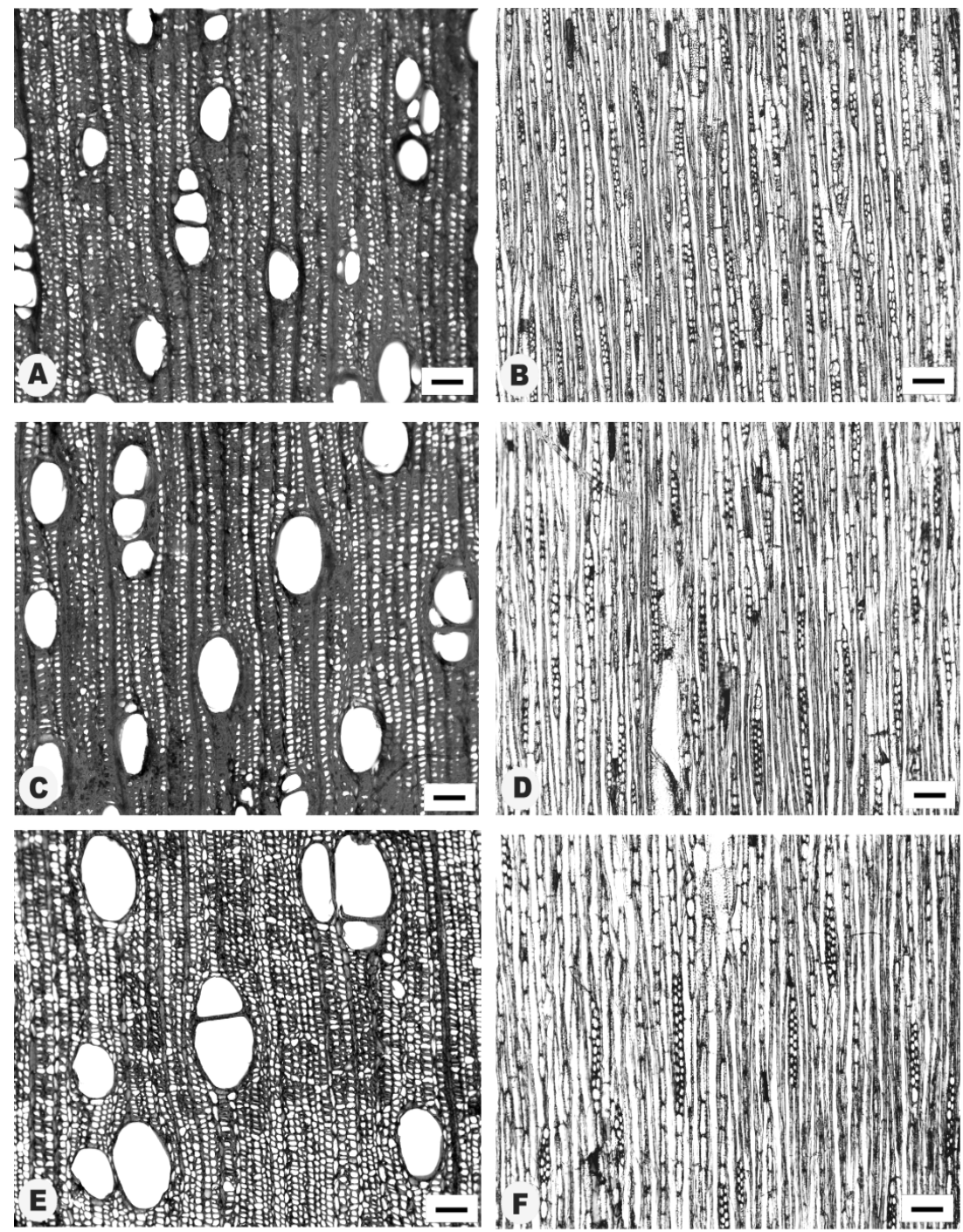

Figura 2. Fotomicrografias do lenho de Croton floribundus. A e B - Secções transversal e tangencial da região da medula. C e D - Secções transversal e tangencial da região central. E e F - Secções transversal e tangencial da região da casca. Notar aumento no diâmetro dos vasos (figuras A, C e E) e diminuição na frequência dos raios no sentido medula-casca (figuras B, D e F). Barra = $100 \mu \mathrm{m}$.

Figure 2. Photomicrographs of Croton floribundus wood. A and B - Transversal and tangential sections from the pith region. $\mathrm{C}$ and $\mathrm{D}$ - Transversal and tangential sections from the central region. $\mathrm{E}$ and $\mathrm{F}$ - Transversal and tangential sections from the bark region. Note increase of vessel diameter (figures $\mathrm{A}, \mathrm{C}$ and $\mathrm{E}$ ) and reduction of the ray frequency in the direction from pith to bark (figures B, D and F). Bar $=100 \mu \mathrm{m}$.

De maneira geral, os valores obtidos de densidade básica e dimensões celulares apresentaram a mesma tendência do padrão geral, observados por espécies de reflorestamento, sendo uma importante 
fonte de informações sobre o comportamento da variação radial das propriedades em estudo, em condições de crescimento natural.

\section{CONCLUSÕES}

- O diâmetro de vasos e a frequência de raios da madeira de C. floribundus aumentaram significativamente no sentido medula-casca.

- A densidade básica, o comprimento de elementos de vaso, o comprimento de fibra, a espessura da parede da fibra, a frequência de vasos, a altura de raios e a largura de raios não apresentaram variações significativas no sentido medula-casca.

\section{REFERÊNCIAS}

ARACHUKU, A. E. A study of lumen diameter variation along the longitudinal axis of wood vessels in Quercus rubra using cinematography. IAWA Bulletin, Leiden, v. 8, n. 1, p. 41-45, 1987.

BASSON, P. Some implications of anatomical variations in the wood of pedunculate oak (Quercus robur L.) including comparisons with comoron beech (Fagus sylvatica L.). IAWA Bulletin, Leiden, v. 8, n. 1, p. 49-166. 1987.

BERLYN, G. P.; MIKSCHE, J. P. Botanical microtechnique and cytochemistry. Iowa: The Iowa University Press, 1976. 326 p.

BOSMAN, M. T. M.; KORT, I.; VAN GENDEREN, M. K.; BASS, P. Radial variation in wood properties of naturally and plantation grown light red meranti (Shorea, Dipterocarpaceae). IAWA Journal, Utrecht, v. 15, n. 2, p. 111-120, 1994.

BUTTERFIELD, R. P.; COOK, R. P.; ADAMS, R.; MORRIS, R. Radial variation in wood specific gravity, fibre length and vessel area for two central american hardwoods: Hyeronima alchorneoides and Vochysia guatemalensis: natural and plantation-grown trees. IAWA Journal, Utrecht, v. 14, n. 2, p. 153-161, 1993.

CARVALHO, P. E. R. Espécies arbóreas brasileiras. Brasília DF: Embrapa Informações Tecnológica; Colombo: Embrapa Floresta, 2003. 2 v.

CRUZ, C. R.; LIMA, J. T.; MUNIZ, G. I. B. Variações dentro das árvores e entre clones das propriedades físicas e mecânicas de híbridos de Eucalyptus. Scientia Forestalis, Piracicaba, n. 64, p. 33-47, 2003.

DENNE, M. P.; HALE, M. D. Cell wall and lumen percentages in relation to wood density of Nothofagus nervosa. IAWA Journal, Utrecht, v. 20, n. 1, p. 23-36, 1999.

DOWES, G. M.; HUDSON, I. L.; RAYMOND, C. A.; DAEN, G. H.; MICHAEL, A. J.; SCHIMLECK, L. R.; EVANS, R.; MUNERI, A. Sampling plantation eucalypts for wood and fibre properties. Downes: CSIRO, 1997. 132 p.

DURIGAN, G.; FIGLIOLIA, M. B.; KAWABATA, M.; GARRIDO, M. A. de O.; BAITELlO, J. B. Sementes e mudas de árvores tropicais. São Paulo: Páginas \& Letras, 2002, 64 p.

FOELKEL, C. E. B.; BRASIL, M. A. M.; BARRICHELO, L. E. G. Métodos para determinação da densidade básica de cavacos para coníferas e folhosas. IPEF, Piracicaba, n. 2/3, p.65-74, 1971.

FUJIWARA, S.; SAMESHIMA, K.; KURODA, K.; TAKAMURA, N. Anatomy and properties of Japanese hardwoods I. Variation of dimensions of ray cells and their relation to basic density. IAWA Bulletin, Leiden, n. 12, p. 419-424. 1991.

GOUVEIA, T. C.; FLORSHEIM, S. M. B.; PASTORE, J. A.; AGUIAR, O. T.; LIMA, I.L. Morfologia, Anatomia do lenho e densidade básica de Croton floribundus Spreg. e Croton macrobothrys. IF Série Registros, São Paulo, n. 31, p. 45-49, 2007.

GREEN, D. W.; WINANDY, J. E.; KRETSCHANN, D. E. Mechanical properties of wood. In: WOODHANDBOOK: wood as an engineering material. Madison: Forest Products Laboratory, 1999. 
(Gen. Tech. Rep. 113: 1-46).

HANS, A. S.; BURLEY, J.; WILLIAMSON, P. Wood quality in Eucalyptus grandis (Hill) Maiden grown in Zambia. Holzforschung,berlin, v. 26, n. 4, p. 38-141,1972.

HILLIS W. H.; BROWN, A. G. Eucalyptus for wood production. Melbourne: CSIRO. 1984. 434 p.

IAWA COMMITEE. List microscope features of hardwood identification. IAWA Bulletin, Leiden, v. 10, n. 3, p. 221-259, 1989.

JANKOWSKY, I. P. Madeira juvenil, formação e aproveitamento industrial. IPEF. Circular técnica, Piracicaba, n. 81, p. 18, 1979.

JOHANSEN, D. A. Plant microtecniques. New York. McGraw-Hill, 1940. 523 p.

LORENZI, H. Árvores brasileiras: manual de identificação e cultivo de plantas arbóreas nativas do Brasil. Nova Odessa: Plantarum, 2002. 382 p.

MAINIERI, C.; CHIMELO, J. P. Fichas de características das madeiras brasileiras. São Paulo: Instituto de Pesquisas Tecnológicas, 1989, 418 p.

OLIVEIRA, J. T. da S.; SILVA, J. de C. Variação radial da retratibilidade e densidade básica da madeira de Eucalyptus saligna Sm. Revista Árvore, Viçosa, MG, v. 27, n. 3, p. 381-385, 2003.

POLLITO, P. A. Z. Dendrologia, anatomia do lenho e "Status" de conservação das espécies lenhosas dos gêneros Cinchona, Croton e Uncaria no Estado do Acre, Brasil. 181 p. Tese (Doutorado em Recursos Florestais) - Escola Superior de Agricultura "Luiz de Queiroz", Universidade de São Paulo, Piracicaba, 2004.

RAO, R. V.; AEBISCHER, D. P.; DENNE, P. Latewood density in relation to wood fibre diameter, wall thickness, and fibre and vessel percentages in Quercus robur IAWA Journal, Utrecht. v. 18, n.2 p. 127138. 1997.

SAS Institute Inc. SAS Procedures Guide: Version 8 (TSMO). Cary, 1999. 33 p.

TERTUlianO, S. S. X.; SILVA, J. A.; PAES, J. B.; ARAÚJO, L. V. C. Equações de massa e determinação da massa específica básica da madeira de Croton sonderianus. Müll.Arg. Brasil Florestal, Brasília, DF, n. 76, p. 15-22, 2003.

TOMAZELLO FILHO, M. Variação radial dos constituintes anatômicos e da densidade básica da madeira de oito espécies de eucalipto. Piracicaba: IPEF, 1983, 99 p. Convênio IPEF/CIA SUZANO DE PAPEL E CELULOSE/DEPARTAMENTO DE SILVICULTURA - ESALQ/USP. Relatório Final

URBINATI, C.; AZEVEDO, A. A.; SILVA, E. A. M.; LISBOA, P. L. Variação estrutural quantitativa no lenho de Terminalia ivorensis A. CHEV, Combretaceae. Acta Botanica Brasilica, São Paulo, v. 17, n. 3. 421-437, 2003.

WIEMANN, M. C.; WILLIAMSON, G. B. Extreme radial changes in wood specific gravity in some tropical pioneers. Wood and Fiber Science, Hanover, v. 20, p. 344-49, 1988.

ZOBEL, B. J.; BUIJTENN, J. P. Wood variation: its causes and control. Berlin: Springer-Variag, 1989. 361 p.

ZOBEL, B. Wood quality from fast-grown plantations.TAPPI Journal, Atlanta, v. 64, n. 1, p. 17-74, 1981. 